\title{
CONTROL y FuGAS EN LA ERA DIGITAL, EN EL DELIRIO DE TURING, de Edmundo Paz Soldán ${ }^{1}$
}

\author{
Control and LEAKS IN THE DIGITAL AGE IN \\ TuRING'S DELIRIUM by EDMUNdo Paz SOLDÁN
}

Sophie Dorothee von Werder

Universidad de Antioquia

Medellín, Colombia

\section{Resumen}

Lectura de la novela El delirio de Turing (2003) como evaluación estética del carácter totalitario de las democracias neoliberales, y de su relación con las tecnologías. Se estudia de qué manera Paz Soldán actualiza la reflexión sobre la lucha entre los poderosos y los oprimidos en un nuevo campo de batalla que es el mundo virtual. El delirio de Turing se compara con la novela anterior, Sueños digitales (2000). Las perspectivas, sin ser excluyentes, representan diferentes enfoques, y no se llega a la misma conclusión. Mientras en la primera, el control del Estado es total, en la más reciente se observan fugas. En El delirio de Turing, el gesto utópico está presente, no obstante es limitado. La sociedad retratada no solo es postdemocrática, también se torna paranoica.

Palabras clave: era de la información; totalitarismo; hacker; novela realista; hiperficción; distopía.

\section{Abstract}

A reading of novel Turing's Delirium (2003) as an esthetic evaluation of the character of neoliberal totalitarian democracies and their relationship to technology. An analysis of how Paz Soldán updates reflections on the struggle between the powerful and the oppressed in a new battlefield set in a Virtual World. Turing's Delirium is compared to Paz's previous novel, Digital Dreams (2000). Viewpoints, bar none, present different approaches without ever arriving at the same conclusion. While in the previ-

\section{Resumo}

Leitura do romance $O$ delírio de Turing (2003) como avaliação estética do carácter totalitário das democracias neoliberais e de sua relação com as tecnologias. Estuda-se de que maneira Paz Soldán atualiza a reflexão sobre a luta entre os poderosos e os oprimidos, em um novo campo de batalha, que é o mundo virtual. $O$ delírio de Turing compara-se com o romance anterior, Sonhos digitais (2000). As perspectivas, sem ser excludentes, representam diferentes enfoques, e não chegam à mesma conclusão. Ainda no

\footnotetext{
${ }^{1}$ Producto derivado del proyecto Literatura e hiperrealidad: un estudio comparado, Etapa II, realizado con el apoyo del Centro de Investigaciones y Extensión de la Facultad de Comunicaciones de la Universidad de Antioquia, adscrito al Grupo de Estudios Literarios (GEL). Forma parte de la Estrategia de Sostenibilidad del Grupo GEL 2014-2015.
} 
ous novel State control is total, the most recent work shows some leaks. Though limited, the utopian gesture is present in Turing's Delirium. Society, as portrayed, is not only post-democratic but has also turned paranoid.

Keywords: era of information; totalitarianism; hacker; realistic novel; hyperfiction; dystopia. primeiro romance, o controle do Estado é total, no mais recente observam-se fugas. Em $O$ delírio de Turing, o gesto utópico está presente, não obstante é limitado. A sociedade retratada não só é pós-democrática, também torna-se paranoica.

Palavras-chave: era da informação; totalitarismo; hacker; romance realista; hiperficção; distopia.

Edmundo Paz Soldán publicó en 2003 El delirio de Turing, su sexta novela, ganadora del Premio Nacional de Novela de Bolivia. Los acontecimientos, como ya había sucedido en novelas anteriores, se desarrollan en Río Fugitivo, ciudad imaginaria en Bolivia, un país neoliberal que es tan tercermundista como hipertecnologizado. Río Fugitivo se encuentra en medio de violentas revueltas populares y protestas contra la globalización, las multinacionales y la privatización de los servicios públicos. ${ }^{2}$

$\mathrm{Al}$ tratarse de una novela que recrea estéticamente un ambiente y se inscribe en la corriente del realismo, este trabajo pretende enfocar, en primera instancia, sus contenidos. Ello considerando que, en la evolución de los estilos, el realismo puede asumirse como una tendencia que no se centra principalmente en el elemento estético, autorreferente de la literatura, sino en la realidad extraliteraria, y puede tener fines extraliterarios (BURCKHARDT, 1982). El delirio de Turing es una novela de ciencia ficción cuyos acontecimientos, sin embargo, se desarrollan en un futuro inmediato y mantienen, por lo tanto, una estrecha relación con el mundo contemporáneo. Es notoria la intención de proyectar en un futuro próximo, ciertos desarrollos que se observan en las sociedades actuales.

En una entrevista de 2008, Paz Soldán hace resaltar que, efectivamente, se siente parte de una tendencia entre los escritores de su generación, de acoger temáticas extraliterarias, y de volver a escribir literatura comprometida. Señala que su preocupación por el impacto de las nuevas tecnologías en la vida contemporánea se refleja en obras como Sueños digitales (PAZ SOLDÁN, 2000), o El delirio de Turing: "En esas novelas también me interesaba, tomando la crisis actual de Bolivia como punto de partida, explorar acerca de la natura-

\footnotetext{
${ }^{2}$ En el caso de Bolivia, las políticas neoliberales se desarrollaron fuertemente en los años noventa y los inicios del nuevo milenio. A partir de 2006, el gobierno de Morales ha venido aplicando medidas para reglamentar el libre comercio y frenar las privatizaciones. Sin embargo, se trata de un proceso paulatino y parcial. Por otro lado, a pesar de que la novela en algunos aspectos alude a situaciones locales, su vigencia no depende del caso de Bolivia en particular, ya que la reflexión que realiza se puede extrapolar a otros países latinoamericanos neoliberales y contemporáneos.
} 
leza del poder y la violencia, entre la democracia de hoy y las dictaduras de nuestro pasado más reciente" (PLAZA, 2008: 104).

Podemos afirmar entonces, que la novela de Paz Soldán hace una evaluación estética de las democracias contemporáneas neoliberales, y actualiza la reflexión sobre la lucha entre los que tienen el poder, y los que no lo detentan. Además, relaciona aspectos políticos y sociales con lo sicológico y lo moral. En esta perspectiva, la novela se ocupa de pasar revista al impacto que causan las políticas neoliberales y el ambiente tecnologizado en la conciencia, y en las relaciones humanas. ${ }^{3}$

El delirio de Turing cobra mucha actualidad y pertinencia, porque analiza la relación que la lucha entre oprimidos y poderosos establece con el mundo virtual, y de esta manera retrata y anticipa en 2003, situaciones y desarrollos que recientemente nos fueron revelados por la organización mediática WikiLeaks y los whistleblower. Hoy en día, estamos conscientes de que los servicios secretos luchan por la hegemonía del espacio virtual, y están preparando verdaderas guerras digitales. Por otro lado, crece el peso del ciberhacktivismo como también el del cibercrimen, y los medios nos informan casi a diario acerca de los ataques cibernéticos de diferentes grupos, como Anonymous o el Estado Islámico con su autodenominado cibercalifato. Observamos que el Internet, el nuevo campo de batalla, se está manejando como un espacio sin ley, no solo por parte de los hackers, sino también de los Estados y sus servicios secretos.

En Eldelirio de Turing, las historias de siete personajes, todos, o hackers, o colaboradores de la Cámara Negra, el organismo de seguridad del Estado, se alternan en cuarenta y cinco capítulos que componen la novela. Miguel Sáenz, personaje que lleva el sobrenombre de Turing, ${ }^{4}$ descifrador de códigos de la Cámara Negra, se entera de que sus jefes, Albert y Ramírez-Graham, lo han utilizado para perseguir y desaparecer a personas inocentes. Albert fue el fundador de la Cámara Negra en tiempos de la dictadura; Ramírez-Graham es su jefe actual. Flavia, la hija de Sáenz, administra la página "TodoHacker", y colabora con Ramírez-Graham en la persecución de Kandinsky, el líder de un grupo de hackers llamado la Resistencia, que combate al gobierno y a las multinacionales. Báez es a la vez empleado de la Cámara Negra y miembro de la Resistencia, y finalmente se sacrifica para salvar a Kandinsky. Ruth, la resentida esposa de Sáenz, se convierte en cómplice del juez Cardona, quien asesina a Sáenz y a Albert, para vengar la desaparición de su prima hermana Mirtha en tiempos dictatoriales.

Nuestro análisis, como señalamos, se va a centrar en primer lugar, en los contenidos de la novela. Sin embargo, cabe destacar que la obra en lo for-

\footnotetext{
${ }^{3}$ Este aspecto ha sido desarrollado por Clark (2010: 101-109) y Montoya Juárez (2013: 76-98).

${ }^{4}$ El sobrenombre alude a Alan Turing, un criptoanalista británico de la primera mitad del siglo XX.
} 
mal también es compleja. Su enfoque narrativo es múltiple. Hay narradores en primera, segunda y tercera persona, variedad de protagonistas, saltos en el tiempo, y diversas perspectivas, voces y lenguajes. Se alternan partes narrativas con diálogos y monólogos, y en varias ocasiones la novela se traslada al ciberespacio, a los chat rooms, o al llamado Playground, un $\mathrm{MUD}^{5}$ o mundo virtual.

Paz Soldán no sólo describe el impacto que tienen las tecnologías sobre la vida de sus personajes; también su obra, a nivel estético, se contagia de ellas. El delirio de Turing imita las estructuras de un texto generado a través de Internet, y por sus características formales fue calificada de "tecno-literatura" (BROWN, 2007: 740) o de "fábula electrónica” (RAMOS GONZÁLEZ, 2003: 470). Consideramos que, a pesar de que aparezca como libro impreso, incluso se relaciona con el género de la hiperficción: ${ }^{6}$ esta novela no tiene centro (no hay personaje central ni un solo narrador). Su estructura no es lineal sino más bien rizomática; se compone de diferentes historias que se cruzan, se remiten - a manera de hiperenlaces - las unas a las otras, forman una red, dinámica y abierta en todo momento. En esta novela, la literatura y la tecnología se compenetran y se escriben la una a la otra.

Paz Soldán retrata un mundo cada vez más impregnado por la tecnología, y relaciona la temática con lo político: compara la dictadura de los años 70, con la versión democrática del mismo gobierno en la actualidad. El personaje de Montenegro, que aparece en varias obras de Paz Soldán, alude a los gobiernos de Hugo Banzer, quien en los ańos setenta instauró una dictadura en Bolivia, y volvió al poder al ganar las elecciones en 1997. Pero no solo Montenegro - dictador de antaño y presidente electo ahora - permite establecer analogías entre la represión de la dictadura, y el control que el actual gobierno ejerce sobre las personas. Son varios los personajes que vivieron durante la dictadura, y en mayor o menor medida colaboraron con ella (Albert, Miguel Sáez, Ruth Sáenz, el juez Cardona). La obra se enmarca entonces en la tradición de la novela del dictador, pero a la vez se abre a una perspectiva más amplia, y se ocupa de los totalitarismos en general.

Según El delirio de Turing, lo que se mantiene estable en la era digital y postdictatorial, son justamente las pretensiones totalitarias del Estado, el sistema de vigilancia y la persecución de los opositores. El totalitarismo parece incluso inherente a la democracia contemporánea, porque las nuevas tecnologías refuerzan tanto las tentaciones, como también las posibilidades reales

\footnotetext{
${ }^{5}$ Multi User Domain.

${ }^{6}$ El término de la hiperficción normalmente se aplica para la literatura escrita en Internet; puede ser escrita por varios autores, y se estructura a través de hiperenlaces.
} 
de control de los Estados y de sus servicios secretos. Al relacionar computadores y terror de Estado, el relato nos remite a teóricos como Paul Virilio o Gilles Deleuze, quienes ya en los ańos 90 advirtieron sobre los peligros e incertidumbres que traería el inicio de una nueva era relacionada con los sistemas y con nuevos mecanismos de control.

Como vaticinó Deleuze en su "Posdata sobre las sociedades de control" (1991), la digitalización de datos y las tecnologías amplían las posibilidades de rastreo hasta no dejar prácticamente nada fuera de control. Las redes de poder experimentan entonces, una importante intensificación y sofisticación de sus dispositivos. El trabajador disciplinado de la sociedad industrial, del que hablaba Foucault, según Deleuze es remplazado por el consumidor controlado (DELEUZE, 1991: 4). También Virilio advierte acerca de una dimensión totalitaria inherente a las nuevas tecnologías, la cual para él, aparece relacionada con la velocidad:

Lo propio de la velocidad absoluta es ser también poder absoluto, control absoluto, instantáneo, es decir, un poder casi divino. Hoy en día, hemos puesto en práctica los tres atributos de lo divino: la ubicuidad, la instantaneidad y la inmediatez; la visión total y el poder total. Esto ya no tiene nada que ver con la democracia, es una tiranía (VIRILIO, 1997: 19, 20).

La "militarización de la información”, de acuerdo a Virilio nos sitúa, incluso, frente a un fenómeno de "totalitarismo sin precedentes" (VIRILIO, 1997: 38, 39). En la novela de Paz Soldán, la democracia contemporánea efectivamente es un simulacro, un disfraz para un Estado que sigue siendo autoritario y criminal. En este sentido, la obra corresponde con la pauta del género contemporáneo de la novela negra, que Forero denomina como "la anomia social” (FORERO QUINTERO, 2015: 121). Albert explica que la Cámara Negra continúa siendo "un digno servicio secreto de inteligencia... Hay democracia hoy. Pero el que quiera podría intentar perpetuarse en el poder... La infraestructura es sólida. El que quiera contar secretos a espaldas del Estado. Tiene los días contados...” (PAZ SOLDÁN, 2003: 97).

Sin embargo, en El delirio de Turing hay quienes enfrentan a este Estado con pretensiones totalitarias. Los opositores, comunistas en la época dictatorial, ahora son los anti-globalizadores, un grupo heterogéneo conformado por piratas informáticos, líderes obreros, indígenas, campesinos, estudiantes, y la gente pobre que protesta por las alzas de las tarifas de la luz. Los hackers, a su vez, se juntan en la llamada Resistencia o Recuperación, que es el nombre del mismo grupo en el Playground, un MUD en el que las personas interactúan a través de avatares. 
Nos permitimos abrir un paréntesis para recordar otra novela de Paz Soldán que, al igual que El delirio de Turing, reflexiona sobre la relación entre tecnologías, políticas neoliberales, y Estado de control. Se trata de la ya mencionada obra, titulada Sueños digitales (2000), y nos parece pertinente aplicar una mirada comparativa a los dos relatos, para ver cómo evalúa cada uno de ellos, la posibilidad para la resistencia en el contexto señalado. Ambas novelas son realistas, y sus mundos ficticios guardan mucha similitud con el contemporáneo.

Sin embargo, cada una examina la postmodernidad desde un ángulo particular. Sueños digitales se lee como un comentario sobre la era de la simulación; El delirio de Turing, en cambio, nos habla de la era de la información. Y aunque las perspectivas de ninguna manera son excluyentes, representan diferentes enfoques, y habría una diferencia importante: mientras en la primera, el control es total, en la segunda se observan fugas, elementos que se escapan. Sueños digitales ficcionaliza ideas fundamentales de la teoría de la simulación de Baudrillard (1978 e 1993), porque aquí, el simulacro domina y lo devora todo, desde el ambiente político hasta las relaciones sociales e incluso íntimas. Con la penetración masiva de la tecnología virtual se genera la desrealización de todo lo que se conocía como real (MONTOYA JUÁREZ, 2007: 888).

El sujeto, en este contexto, es un sujeto controlado, además desinformado y desorientado, en consecuencia es objeto más que sujeto. Aun el personaje central de la novela, experto en desapariciones digitales y colaborador con el organismo de seguridad del Estado, finalmente se convierte en otra víctima del sistema implacable al que contribuyó. Montenegro se deshace de las pruebas, y luego de las personas que le ayudaron en eso. Por otro lado, los muchos suicidios que ocurren en esa novela se convierten en evento público y medial, son asimilados al ámbito de las imágenes y quedan despojados de toda posibilidad de denuncia o oposición (VON WERDER, 2015: 96). El ambiente hiperreal tiene un poder arrasador del que nada ni nadie se escapa, por eso, en Sueños digitales, la resistencia no es posible.

Como ya señalamos, en el mundo narrado de El delirio de Turing, bajo el rótulo de la democracia también se renueva la pretensión totalitaria de las dictaduras. Sin embargo, observamos que aquí, aunque los mecanismos de la represión son nuevos y más intensos, habría al menos una buena noticia: las posibilidades de subvertirlos también se multiplican. Las maneras de protestar de antes, como las manifestaciones, a veces se mantienen, pero son obsoletas.

La ciudad ansía tanto la modernidad que al hacerlo sus habitantes no hacen otra cosa que ser tradicionales. En un universo regido por múltiples temporalidades históricas, ellos sueñan con la modernidad de la televisión por cable, pero están anclados en el pasado premoderno de huelgas y protestas callejeras. (PAZ SOLDÁN, 2003: 177) 
La novela muestra que la lucha, en un mundo cada vez más controlado por computadores, ya no se libra en las calles; se traslada a los sistemas, las redes, el mundo de los códigos. La guerra ahora es electrónica y las nuevas formas de subversión tienen cercanía con el cibercrimen. Ramírez-Graham, consciente de los desafíos de la nueva época, reestructura la Cámara Negra; deja de contratar lingüistas y se rodea de analistas informáticos para "hacerla útil para este nuevo siglo" (PAZ SOLDÁN, 2003: 43). Debido a que el hackeo en la época neoliberal viene a remplazar el criptoanálisis de los años setenta, el criptoanalista Sáenz ahora es relegado al Archivo General de la Cámara Negra, y se siente como una "anacrónica reliquia" (PAZ SOLDÁN, 2003: 17) frente a los colegas jóvenes, expertos en informática.

Los hackers en este contexto se convierten en figuras poderosas, muy peligrosas, tan admiradas como temidas. Sus armas son el espionaje y los ataques con virus informáticos. Sus objetivos, la obtención de información secreta, la destrucción de los sistemas del enemigo, o el control sobre los mismos. Varios personajes centrales, como Kandinsky, Báez y Rafael, son hackers. Flavia se mantiene muy cercana a su esfera, porque simpatiza con sus objetivos y administra el website "Todo Hacker". En lo ético, el hacker es una figura difusa y oscilante. Puede ser un simple criminal, como puede ser un héroe que desafía el Estado de control. Esta ambigüedad se refleja en Kandinsky: de origen muy humilde, se dedica durante un tiempo al robo de números de tarjetas de crédito, contraseñas de cuentas bancarias y números de seguros de vida. Sin embargo, se va convirtiendo en un hacker con ética que se opone a un gobierno autoritario, a la globalización y las multinacionales. Finalmente se sirve de métodos ilegales, pero persigue el bien.

Brown seńala otra ambivalencia en la figura del pirata informático al subrayar que "hackers move between states of embodiment and disembodiment" (BROWN, 2006: 116), es decir son seres oscilantes entre el estado físico y otro incorpóreo. Por ser invisibles y realizar desde el anonimato, maniobras incomprensibles para la gente común, fácilmente los hackers se convierten en mito o leyenda. Esto aumenta su atractivo, su influencia y su poder. Al mismo Kandinsky "le gusta cómo suena esa palabra misteriosa. Hacker. Le da un aire peligroso, inteligente, transgresor. [...] Los hackers ingresan a territorios prohibidos por la ley, y de una vez, se burlan del poder" (PAZ SOLDÁN, 2003: 64). Ramírez-Graham a su vez, cuando sus colaboradores hablan de la Resistencia, detecta un tono de admiración, y piensa que "ése es uno de los problemas: la gente que trabaja para él está seducida por la idea romántica del hacker que divulgan los medios" (PAZ SOLDÁN, 2003: 86, 87). 
Ramírez-Graham reconoce haber llegado a Río Fugitivo "con la arrogancia de un pasado como experto de la National Security Agency, al que el trabajo de salvador de la Cámara Negra de Bolivia le quedaba chico. Y ahora se encontraba jaqueado por un hacker tercermundista" (PAZ SOLDÁN, 2003: 42), por "un hacker local, que alguna vez fue capaz de infiltrarse en los sistemas de seguridad del Pentágono [...]" (PAZ SOLDÁN, 2003: 87). RamírezGraham se siente humillado ${ }^{7}$ y es consciente de que el potencial subversivo del hacker es enorme, porque desafía no solo un Estado, sino todo el orden mundial: puede atacar y desestabilizar el primer mundo desde el tercer mundo.

Aparte de eso, los piratas ni siquiera tienen que contar con una determinada trayectoria académica o laboral. Pueden ser hombres muy jóvenes, incluso adolescentes que ponen en jaque a la Cámara Negra sin tener mucha preparación ni herramientas sofisticadas. Se le advierte a Ramírez-Graham que "no podemos contra hackers medianamente preparados. Ni siquiera podemos leer fácilmente emails encriptados con un buen software de los que se compran en la calle" (PAZ SOLDÁN, 2003: 87). Es decir, casi cualquiera podría ser un hacker. En la Cámara Negra, se especula acerca de la identidad de Kandinsky, pero en la época del espionaje, es imposible saber quién es quién, ni hay manera de prever desde qué lugar están preparando el próximo ataque:

- Nadie tiene una pista. Puede ser cualquiera.

- Puede, incluso, estar trabajando aquí.

- Puede ser el jefe. (PAZ SOLDÁN, 2003: 195)

Las consideraciones hechas hasta aquí, nos llevan a la pregunta de si la novela de Paz Soldán proyecta una visión utópica o más bien distópica de la sociedad que retrata. Jorza considera El delirio de Turing una obra "ilustrativa para un nuevo tiempo histórico, de aparición de nuevas formas de hacer política". Ella valora la configuración de una "comunidad alternativa" (JORZA, 2012: 58) en el relato, y resume que "El delirio de Turing como utopía política participa [...] no sólo en el rescate del imaginario utópico sino también en la vislumbre de una sociedad futura más democrática y una forma más participativa de ciudadanía" (JORZA, 2012: 63).

Sin negar la evidente relación entre la Resistencia con respecto a una nueva izquierda y una nueva manera de hacer oposición que se narra en la novela, son tres las razones por las que consideramos que de la novela se desprende una visión menos optimista que la que Jorza ve proyectada allí. Por un lado, Paz Soldán retrata un Estado que ha logrado niveles de control sin

${ }^{7}$ Ramos Ortega desarrolla este punto (2010: 239). 
precedentes, en el cual las condiciones para la oposición son muy difíciles. Por otro lado, la visión de una "comunidad alternativa" es cuestionable porque el ambiente de incertidumbre se ha generalizado y afecta también al grupo de los hackers. Mientras en la Cámara Negra se está consciente de que cualquiera puede ser Kandinsky, Flavia, al conocer a Rafael, piensa que este podría ser Kandinsky, o bien puede ser cualquiera: "¿Será un hacker? Cuál de ellos? ¿De la Resistencia? ¿Un rata? ¿O ambas cosas?” (PAZ SOLDÁN, 2003: 31). Flavia no lo puede saber porque entre los hackers, por temor a las delaciones se mantiene el estricto anonimato. Ni siquiera las figuras principales en el interior de la Resistencia conocen personalmente a Kandinsky: "nadie sabe quién es él, nadie conoce su rostro” (PAZ SOLDÁN, 2003: 79).

El encuentro físico entre los piratas informáticos no es posible y la comunicación es del todo mediada, además que encriptada, por razones de seguridad. Por eso, entre los miembros de la Resistencia, a pesar de que compartan objetivos y sean solidarios entre ellos, no pueden establecerse cercanía, ni compañerismo, ni amistad. Se trata de una comunidad abstracta; posthumana finalmente, porque no existe sino por mediación tecnológica.

Aparte de eso, observamos que las estructuras autoritarias son omnipresentes y también afectan a la Resistencia, es decir hay elementos distópicos en el interior de la misma: Rafael le explica a Flavia que Kandinsky tiene una "despiadada manera de acallar todo tipo de disenso en la organización. La Resistencia no tolera resistencia interna" (PAZ SOLDÁN, 2003: 209). Flavia lo cree incluso responsable de la muerte de los hackers Vivas y Padilla.

\section{Conclusiones}

El delirio de Turing compara el totalitarismo de las dictaduras de los años 70 , con otro contemporáneo que subyace en los sistemas democráticos y aparece íntimamente ligado a las nuevas tecnologías. A diferencia de la novela anterior, Sueños digitales, la cual recrea estéticamente un ambiente marcado por la simulación en el que la resistencia ya no es posible, El delirio de Turing reflexiona sobre la era de la información y llega a otra conclusión: El control del Estado aquí no es total; se observan fugas. El gesto utópico está entonces presente en El delirio de Turing, porque la red se representa como un espacio alternativo para la oposición político-económica, y los hackers desarrollan un potencial subversivo muy importante en la novela. Sin embargo, la incertidumbre, el aislamiento y la falta de orientación son notorios en todos los personajes de la novela. Como en la nueva era, el bien en pugna es la información, el poder equivale al acceso y manejo de la misma, y todos aplican el lema de los espías: "descubra los secretos del otro, encubre los tuyos". La información entonces se mantiene oculta o se disfraza: en la comunicación 
se usan diferentes códigos y claves ininteligibles para el común de la gente. El poder del hacker, en este contexto consiste en buena parte en su capacidad para sembrar la desconfianza. No se conocen su identidad, su lugar de estancia o sus intenciones, y siempre puede ser muy peligroso.

El "delirio de Turing" al que alude el título de la obra cobra un doble sentido: En un primer momento se trata de un delirio de grandezas, cuando Sáenz desconoce que el sobrenombre le fue dado por su similitud con una máquina, y lo atribuye a sus habilidades en el criptoanálisis. Sin embargo, en la era de la información el delirio de Turing se torna un delirio de persecución, cuando el mismo personaje se da cuenta de que lo han engañado y utilizado para perseguir a inocentes, cuando se entera de que lo están filmando cada vez que se esconde en un rincón para orinar en una bolsa plástica, y sobre todo cuando comienzan a llegarle mensajes amenazantes que le recuerdan que tiene sus manos manchadas de sangre (PAZ SOLDÁN, 2003: 23).

La guerra informática es sucia, no tiene ley. La desinformación y la mentira dejan de ser la excepción y se vuelven normalidad. El costo a nivel humano es alto y lo pagan todos. También en la comunidad de los piratas informáticos se mantiene el anonimato; el temor hace imposible cualquier acercamiento personal. Debido a esta situación, se trata de una comunidad posthumana que existe única y exclusivamente a través de la mediación tecnológica. Por eso la visión que proyecta El delirio de Turing, es en buena medida distópica. Los personajes conviven en una sociedad no solo postdemocrática, sino también paranoica. La duda desarrolla un poder inmenso, porque destruye la relación humana. La era de la información, de acuerdo con la novela de Paz Soldán, se convierte en una era de la desconfianza.

\section{Referencias bibliográficas}

BAUDRILLARD, Jean. Cultura y simulacro. Trad. por Antoni Vicens y Pedro Rovira. Barcelona: Kairós, 1978.

. El intercambio simbólico y la muerte. Trad. por Carmen Rada. Caracas: Monte Ávila Editores, 1993.

BROWN, J. Andrew. “Techno-escritura: Literatura y tecnología en América Latina”. Revista Iberoamericana. V. LXXIII, n. 221, oct.-dic. 2007: 735-741.

. "Hacking the past: Edmundo Paz Soldán's El delirio de Turing and Carlos Gamerro's Las Islas". Arizona Journal of Hispanic Cultural Studies. V. 10, 2006. Disponible: $<$ http://www.jstor.org/discover/10.2307/20641799?uid=2129\& uid=2\&uid=70\&uid=4\&sid=21102683840537>. Recuperado el 15/10/15.

BURCKHARDT, Jacob. La cultura del renacimiento en Italia. Madrid: Edaf, 1982.

CLARK, Steven. "Marcando la literatura posmoderna: Globalización y tecnología en El delirio de Turing por Edmundo Paz Soldán”. Divergencias. Revista de Estudios Lingüisticos y Literarios. v. 8, n. 2, 2010: 101-109. Disponible: 
<http://divergencias.arizona.edu/sites/divergencias.arizona.edu/files/articles/ ClarkGlobalizacionPazSoldan.pdf>. Recuperado el 15/10/15.

DELEUZE, Gilles. Posdata sobre las sociedades de control. 1991. Disponible: <http:// www.fundacion.uocra.org/documentos/recursos/articulos/Posdata-sobre-lassociedades-de-control.pdf>. Recuperado el 08/03/15.

FORERO QUINTERO, Gustavo. "Anarquismo sin fronteras en De paso, de Paco Ignacio Taibo II". In: (ed.). Fronteras del crimen. Globalización y literatura. Bogotá: Planeta, 2015.

JORZA, Diana Roxana. "La figuración de una utopía política en El delirio de Turing de Edmundo Paz Soldán”. Revista Hispánica Moderna. v. 65, n. 1, Pennsylvania: University of Pennsylvania, 2012: 47-64.

MONTOYA JUÁREZ, Jesús. "Escrituras de lo virtual en la narrativa hispanoamericana del siglo XXI: la utopía aterradora en Edmundo Paz Soldán, Gabriel Peveroni y Andrés Neuman”. RILCE, v. 29, n. 1, 2013: 76-98.

"Ni apocalípticos ni integrados: Medios audiovisuales en tres narradores del sur de América". Revista Iberoamericana, v. LXXIII, n. 221, oct.-dic. 2007: 887-902.

PAZ SOLDÁN, Edmundo. El delirio de Turing. Buenos Aires: Alfaguara, 2003.

. Sueños digitales. Madrid: Alfaguara, 2000.

PLAZA, Caridad. "Diálogo de la Lengua”. Quorum. Revista de Pensamiento Iberoamericano. Universidad de Alcalá, 20, 2008. Disponible: <http://www. elboomeran.com/upload/ficheros/noticias/mano_iwasaki_soldan.pdf>. Recuperado el 15/10/15.

RAMOS GONZÁLEZ, Rosario. "La 'fabula electrónica’: Respuestas al terror político y las utopías informáticas en Edmundo Paz Soldán”. MLN, 118, 2, Hispanic Issue, Baltimore: The John Hopkins University Press, 2003.

RAMOS ORTEGA, Belén. "Avatares literarios: Edmundo Paz Soldán o las nuevas tecnologías en la narrativa actual”. In: Sociedad Española de Literatura General y Comparada. XVIII, Alicante: Universidad de Alicante, 2010.

VIRILIO, Paul. El cibermundo, la politica de lo peor. Entrevista con Philippe Petit. Trad. por Mónica Poole. Madrid: Ediciones Cátedra, 1997.

VON WERDER, Sophie Dorothee. "Simulacro, violencia e intercambio simbólico en Sueños digitales, de Edmundo Paz Soldán”. Taller de Letras, Pontificia Universidad de Chile, 56, 2015.

Sophie Dorothee von Werder é Professora de Literatura hispano-americana, Literatura comparada e Linguística na Universidade de Antioquia, Medellín, Colombia. Diretora do Grupo de Estudos Literários (GEL). Doutora em Literatura Latinoamericana pela Universidade de Concepción, Chile. Licenciada em Germanística pela Universidade de Heidelberg, Alemanha. Tradutora Oficial na Alemanha e na Colômbia. E-mail: svonwerder@gmail.com.

Recebido em: 10/09/2015 Aprovado em: 10/10/2015 